\title{
RATING DE COOPERATIVAS AGROPECUÁRIAS: UMA CONTRIBUIÇÃO METODOLÓGICA ${ }^{1}$
}

\author{
Davi Rogério de Moura Costa \\ Sigismundo Bialoskorski Neto ${ }^{3}$
}

\begin{abstract}
Resumo - Problemas macroeconômicos e de política agrícola provocaram impactos no desempenho financeiro das cooperativas agropecuárias, o que as levou a obter recursos junto a terceiros. Entretanto, a existência de assimetria de informações entre seus diretores, cooperados e mercado financeiro requer uma classificação de rating. Diante disso, é objetivo deste artigo apresentar uma proposta de metodologia de rating que sirva de sinalizadora das informações das cooperativas. A metodologia foi desenvolvida e aplicada experimentalmente em uma cooperativa localizada no Estado de São Paulo, o que permitiu concluir que ela é exeqüível e representa, adequadamente, a realidade da cooperativa.
\end{abstract}

Palavras-chave: metodologia de rating, cooperativas agropecuárias, Brasil.

Este trabalho é parte da dissertação de mestrado em Economia Aplicada, em andamento, no Departamento de Economia, Administração e Sociologia, ESALQ-USP. Os autores agradecem à Organização das Cooperativas do Estado de São Paulo (OCESP) e ao Serviço Nacional de Aprendizagem do Cooperativismo (SESCOOP$\mathrm{SP}$ ), pelo apoio financeiro a estas atividades de pesquisa e investigação. Recebido em 26/09/2005. Aceito em 25/11/2005.

2 Professor de Economia no Centro Universitário UNASP - Eng. Coelho - Mestre em Economia aplicada pela ESALQ-USP - Rua João Sampaio, 2517, Edifício Arcadas, Apartamento 74, Bairro São Judas, Piracicaba SP. CEP: 13400-510 - E-mail: drmcosta@esalq.usp.br / davi.costa@unasp.edu.br.

3 Professor Livre Docente do Departamento de Economia da Faculdade de Economia, Administração e Contabilidade de Ribeirão Preto - FEARP-USP. - Av. Bandeirantes 3.900, Bloco C, sala 67, Bairro Monte Alegre - Ribeirão Preto - SP. CEP: 14020-260- E-mail: sigbial@usp.br. 


\section{Introdução}

De acordo com a Aliança Cooperativa Internacional (ACI, 1995), cooperativa é uma associação autônoma de pessoas que se unem, voluntariamente, para satisfazer às aspirações e necessidades econômicas, sociais e culturais comuns, por meio de uma empresa de propriedade coletiva e gerida democraticamente.

Segundo Menegário (2000), essas organizações, com raras exceções, encontravam-se, no final da década de noventa, em situação de elevado endividamento, notadamente em operações de longo prazo, contraídas junto ao sistema financeiro. Este autor ainda apontou que, em 1999, a situação dos produtores rurais não permitia que eles aportassem recursos para capitalizar suas cooperativas.

Diante desse quadro e da instabilidade de renda na agricultura, as estratégias de alavancagem financeira das cooperativas agropecuárias brasileiras focaram a captação de recursos para seu funcionamento junto a terceiros, mais especificamente às entidades bancárias ou fornecedores. Assim, a forma como elaborar seu rating, que aponta seu nível de risco e previsão de uma possível inadimplência, torna-se importante.

Nesse sentido, Bialoskorski Neto (2000) afirmou que nessas sociedades, por não terem fins lucrativos, a análise dos indicadores de desempenho deveria ser tratada de forma diferente, pois não se devem analisar somente os indicadores econômico- financeiros, mas também os que se referem ao seu desempenho social.

Diante da problemática brevemente exposta, é objetivo central deste artigo apresentar uma proposta de metodologia de rating específico a cooperativas agropecuárias brasileiras, a qual sirva de mecanismo de redução no nível de assimetria de informação entre os gestores das cooperativas, cooperados e mercado. Para isso, este texto está dividido em cinco partes. Na primeira, são apresentados a introdução, o objetivo e a metodologia; na segunda, é exposto o referencial teórico do trabalho, 
que aborda o que seria assimetria de informação e indica o índice rating como possível solução; na terceira, é demonstrada como a literatura tratou a previsão de inadimplência e risco de crédito das cooperativas agropecuárias brasileiras, nas duas últimas décadas;na quarta e na quinta parte, apresentam-se, respectivamente, a proposta metodológica e as conclusões.

\section{Referencial teórico}

Para Milgrom e Roberts (1992), a assimetria de informação ocorre nos mercados e em relações contratuais em que um agente econômico possui uma informação que o outro desconhece, cuja obtenção implica custos.

Nesta linha, Farina (1997) esclareceu que o surgimento de teorias que tratavam da existência de informações assimétricas adveio do relaxamento da hipótese da informação perfeita. Enfatizou que os trabalhos de Arrow (1969), Akerlof (1970) e Spence (1973) contribuíram para sua consolidação e que, mais tarde, Rothschild e Stiglitz (1976) e Stiglitz e Weiss (1981) deram continuidade no tema, além de outros.

Pindyck e Rubinfeld (2002) afirmaram que a assimetria de informação deturpa o funcionamento do mercado, e sua principal conseqüência é a não realização de transações econômicas entre detentores de produtos de alta qualidade e compradores de produtos que desconhecem esse atributo do produto.

Ao fazer uma análise dos trabalhos realizados nesta área, é possível classificar a assimetria de informação em risco moral e seleção adversa. Para entender este último, é importante conhecer os resultados dos trabalhos desenvolvidos por Akerlof (1970), Spence (1973) e Stiglitz e Weiss (1981). 
Akerlof $(1970)^{4}$ mostrou que a seleção adversa compromete o funcionamento do mercado, quando provoca redução nos valores que os agentes estariam dispostos a pagar por determinada mercadoria, fazendo com que permaneçam naquele somente os produtores de produto com baixa qualidade.

O trabalho de Stiglitz e Weiss (1981) corrobora os resultados de Akerlof (1970), quando demonstra que a seleção adversa provoca racionamento do mercado e, conseqüentemente, aumento nas taxas de juros, conduzindo para esse mercado somente os tomadores de crédito com baixa capacidade de pagamento.

Spence $(1973)^{5}$ propôs, como solução à seleção adversa, mecanismos de sinalização para atenuar a assimetria de informação entre os agentes. Nessa situação, um agente de mercado envia um sinal ao outro que está disposto a transacionar, transmitindo informações relevantes para realização do contrato.

Para Bergamini Júnior (2000), a teoria da administração financeira define rating como um processo de análise que procura determinar a capacidade e a vontade de uma entidade vir a cumprir, no período adequado e na íntegra, determinadas responsabilidades, podendo ser estas informações resumidas, sintéticas e comparáveis.

Considerando que a palavra risco representa a probabilidade de ocorrer um evento não desejado e que rating é o processo de análise deste, então o resultado final do processo de avaliação de uma organização determinará a probabilidade de a empresa não cumprir suas responsabilidades junto aos agentes do mercado.

\footnotetext{
4 Akerlof publicou em 1970 o artigo intitulado “The Market for 'Lemons': Quality Uncertainty and the Market Mechanism" e apresentou como a falta de informação sobre os carros velhos, denominados de limão, afetava o mercado americano.

5 SPENCE publicou, em 1973, trabalho intitulado "Market signaling: information transfer in hiring and related processes" e apresentou a educação como mecanismo de sinalização para a qualidade da mão-de-obra.
} 
Portanto, o rating corporativo pode ser considerado como parâmetro importante no relacionamento contratual entre dois agentes econômicos ${ }^{6}$. Assim, é elaborado a pedido de firmas interessadas em divulgar ao mercado o seu nível de risco, com vistas em aumentar a transparência e a confiabilidade na sua gestão, funcionando como sinalizador de mercado.

Segundo a Moody's (2004), as vantagens de se obter um bom rating seriam: a) menor valor de prêmio ou spread nas operações; b) maior valorização das ações; c) maior atratividade de investimento externo; d) melhoria na imagem institucional; e e) maior facilidade na obtenção de financiamentos.

Conforme Silva (1997) e Weston e Brigham (2000), a análise do risco de crédito de uma empresa deve ser feita com base nos critérios denominados "Cs" do crédito, quais sejam, caráter, capacidade, condições, conglomerado, capital, colateral e classificação. Diante disso, é possível admitir que as metodologias de rating os utilizam como referencial de análise.

O "C" - Condição, segundo Silva (1997), deve refletir informações sobre tendências econômicas do mercado de atuação da empresa; o "C" Capital refere-se à situação econômica e financeira da organização e informa se a empresa tem possibilidade de saldar sua dívida; e o "C" Conglomerado, por sua vez, agrega informações sobre relação societária entre a empresa.

O "C" - Caráter, de acordo com Weston e Brigham (2000), está relacionado com a intenção de pagamento do tomador, ou seja, a vontade do cliente de honrar suas obrigações; e "C" - Capacidade é um julgamento subjetivo das possibilidades de pagamento do empréstimo por parte do cliente e deve ser observada com base nos registros passados dos clientes e nos seus métodos empresariais. Já o "C" - Colateral informará sobre o nível de garantias que o solicitante de crédito poderá oferecer para determinada operação financeira.

O rating corporativo pode representar o risco de crédito de uma organização como um todo, e não especificamente de uma única operação. 


\section{Risco e inadimplência de cooperativas agropecuárias brasileiras}

Dada a necessidade de tratar as cooperativas de forma diferenciada, conforme observou Bialoskorski Neto (2000), Costa e Bialoskorski Neto (2005) fizeram uma revisão teórica de trabalhos que tinham o objetivo de calcular o risco de crédito, solvência ou prever situações de inadimplência das cooperativas agropecuárias brasileiras, a partir do início da década de noventa.

Estes autores consideraram os trabalhos de Araújo (1996), Requejo (1997), Menegário (2000), Gimenes e Opaso (2001) e Bialoskorski Neto et al. (2003), como principais e informaram que os trabalhos conduzidos por Araújo (1996) e Gimenes e Opaso (2001) não levaram em consideração a especificidade do empreendimento cooperativo, como sugeriram Pinho (1986) e Bialoskorski Neto (2000), ao contrário, utilizaram apenas indicadores da parte econômica e financeira da organização. Já os de Requejo (1997), Menegário (2000) e Bialoskorski Neto et al. (2003) abordaram características específicas desses empreendimentos.

Requejo (1997) concluiu, em relação à especificidade do empreendimento cooperativo, que quanto maior a transação do cooperado com a cooperativa, menor a probabilidade de esta atingir resultados negativos. Já Menegário (2000) demonstrou que quando indicadores socioeconômicos são adicionados aos modelos de previsão de inadimplência, o índice de acerto aumentava. No estudo que conduziu, o índice de acerto passou de $77,42 \%$ para $83,87 \%$.

Bialoskorski Neto et al. (2003) constataram que as variáveis que explicam o desempenho social das cooperativas são as mesmas que explicam o desempenho econômico destas e concluíram que o que explica o seu desempenho social é o resultado econômico e financeiro.

De acordo com Costa e Bialoskorski Neto (2005), do total de indicadores utilizados nos trabalhos dos autores citados, apenas uma parte, 
aproximadamente um terço, se aplica especificamente às cooperativas; somente seis indicadores, dentre 27 no total, foram usados em ao menos dois trabalhos; destes, apenas um (Liquidez Corrente - LC) foi usado por três; e somente um (Participação em Assembléia Geral Ordinária) não estava relacionado com a área econômica e financeira.

Com base nos resultados, esses autores concluíram que não havia definição clara, na literatura, de quais indicadores, mesmo os financeiros, deveriam ser usados para avaliar o risco de cooperativas agropecuárias brasileiras, haja vista a baixa utilização de indicadores iguais por metodologias diferentes.

Acrescentaram ainda o fato de existir somente um indicador (Participação em Assembléia Geral Ordinária) não relacionado com a parte financeira da cooperativa. Corroboraram os resultados de Bialoskorski Neto et al. (2003), quando relataram que o desempenho financeiro dessas organizações afetava seu desempenho social. Porém, enfatizaram que ainda faltavam elementos para entender a relação existente entre o desempenho econômico-financeiro e social.

Em se tratando de modelos para efetuar previsão de risco e inadimplência de cooperativas agropecuárias brasileiras, Costa e Bialoskorski Neto (2005) informaram que o Logit foi o mais utilizado, mas o que obteve maior nível de acerto foi o de Redes Neurais, conduzido por Bialoskorski Neto (2000).

Gimenes e Opaso (2001), ao compararem o modelo Logit com a Análise Discriminante, apontaram que o último obteve maior índice de acerto nas cooperativas agropecuárias do Paraná. 


\section{Proposta metodológica}

A metodologia foi dividida em cinco grupos de indicadores denominados capacidade da organização; capital da organização; caráter da organização; colateral e conglomerado; e condição de mercado. Esses grupos congregaram 12 tópicos de assuntos-chave, que, por sua vez, são mensurados por meio de 27 indicadores? .

Os indicadores foram escolhidos ou criados, e esta escolha se deu com base nos índices sugeridos nas metodologias de elaboração de rating das agências que prestam esse serviço a empresas brasileiras e em trabalhos que propunham avaliação de cooperativas agropecuárias. Os demais foram criados de acordo com a necessidade do que se pretendia diagnosticar na organização cooperativa.

Cada indicador analisado recebeu um peso, de acordo com o resultado, que variou de 3, 2 e 1, em ordem decrescente. Assim, por exemplo, se o valor obtido for o mais adequado para garantir o cumprimento do contrato pela cooperativa, receberá peso três; se a sua contribuição for média, valor dois; e se o resultado apontar dificuldades para cumprir o contrato, peso um.

Os tópicos de assuntos-chave recebem nota que varia entre "a", "b" e "c", de acordo com os pesos recebidos por cada um dos indicadores que compõem o tópico. Pela equação (1) calcula-se a porcentagem de pontos obtidos pela cooperativa para cada assunto-chave.

No anexo A são apresentadas todas as fórmulas para calcular os indicadores. 
$P_{o}=\left(\frac{\sum_{1}^{n} P_{n}}{3 n}\right) \times 100$

em que Po é porcentagem de pontos obtidos nos indicadores analisados; $\mathrm{Pn}$, ponto obtido no indicador n; e n, número de indicadores utilizados no tópico-chave analisado.

A distribuição das notas foi feita com base nos quartis de uma distribuição normal, pois se pretendeu considerar na nota a freqüência dos pesos recebidos em cada indicador. Assim, se $\mathrm{P}_{0}$ e" 75\%, a cooperativa receberia nota "a"; se $\mathrm{P}_{\text {o }}$ estivesse entre $50 \%$ e $75 \%$, nota "b"; e se $\mathrm{P}_{\text {o }}$ fosse menor que $50 \%$, nota "c".

Finalmente, as notas dos grupos poderão variar entre "A", "B" e "C", de forma a considerar a freqüência das notas recebidas pela cooperativa nos tópicos-chave e nos pesos dos indicadores compreendidos no grupo. Pela equação (2) calcula-se a nota.

$T P=\left[\frac{3\left(\sum_{1}^{n} X_{a}\right)+2\left(\sum_{1}^{n} X_{b}\right)+\left(\sum_{1}^{n} X_{c}\right)}{3 n}\right] \times 100$

em que TP é total de pontos obtidos com base nas notas recebidas em cada tópico de assuntos-chave; $X_{a}$, número de tópicos que receberam nota "a"; $X_{b}$ número de tópicos que receberam nota " $b$ "; $X_{c}$, número tópicos que receberam nota "c"; e n, número de tópicos de assuntoschave analisados no grupo.. 
Se TP e" $75 \%$, a cooperativa receberia nota "A"; se TP estivesse entre $50 \%$ e $75 \%$, nota "B"; e se TP fosse menor que $50 \%$, nota " $\mathrm{C}$ ".

O grupo capacidade da cooperativa indica se a cooperativa cumpria seus compromissos no curto prazo e no ambiente institucional vigente. Para gerar essa informação, são diagnosticados os seguintes tópicos de assuntos-chave: capacidade de a cooperativa cumprir sua função social (ES); estratégia empresarial da cooperativa com o cooperado (EECC); eficiência empresarial enquanto organização (EEO); e profissionalização e qualidade da governança (PQG).

A avaliação da capacidade da cooperativa para cumprir sua função social (ES) é direcionada para a relação econômica entre a cooperativa e o cooperado, ou seja, o desempenho de atividades econômicas que proporcionem aumentos na renda do associado, oportunidade de comercialização da produção e fornecimento de insumos, bens e serviços necessários à atividade econômica do sócio, com vistas em impulsionar seu desempenho econômico e financeiro.

Os indicadores que compõem esse tópico são índice de atividade econômica do cooperado com a cooperativa (ATc); índice de abrangência do quadro social (AQS); e índice de participação dos cooperados em assembléia geral (PAG). Todos esses indicadores irão variar de zero e um e, quanto mais próximo de um, melhor será a eficiência social da cooperativa.

Com base no valor de cada um desses indicadores, é definida a nota para a eficiência social da cooperativa.

O tópico eficiência empresarial do empreendimento cooperativo (EECC) depende da forma como a cooperativa gera sua relação com o cooperado. Portanto, são avaliadas as estratégias empresariais adotadas pela cooperativa junto aos cooperados e se estas contribuem para aumentar a capacidade da organização para cumprir compromissos contratados. 
Para gerar informações sobre tópico foram escolhidos os indicadoresíndice de cobertura do financiamento efetuado pela cooperativa ao cooperado (CFCC); estratégia de capitalização da cooperativa via cooperado (ECVC); planos de devolução do capital social ao cooperado (PDCC); remuneração do capital social dos cooperados (RCSC); prestação de serviços ao cooperado (PSC); e ciclo financeiro da cooperativa junto ao cooperado (CFINC).

O CFCC apresenta a forma como esta atua junto ao cooperado, no que se refere ao financiamento. Quanto maior o CFCC, mais seguro será o sistema de garantia das operações de crédito fornecido ao associado.

$\mathrm{O}$ indicador ECVC informa se a cooperativa possui programas formais de capitalização via cooperado e se estes podem ser usados como garantia das operações da cooperativa. Sua análise é feita por meio de análise do estatuto social da cooperativa e de entrevistas com os diretores da cooperativa.

O PDCC é avaliado para diagnosticar se a cooperativa planeja a restituição do capital do cooperado e se essa estratégia não compromete sua estrutura financeira. Sua análise se dá com base em entrevistas com diretores e averiguações no estatuto social da organização.

A RCSC é realizada para saber se a cooperativa utiliza essa estratégia para atrair o capital do cooperado, mas se isso não expõe suas finanças ao risco, por meio de entrevistas e análises de controles internos da cooperativa.

O PSC é diagnosticado com a finalidade de averiguar se a cooperativa tem prestado serviços ao cooperado como estratégia de atratividade, mas se esta não compromete a sua estrutura financeira.

O CFINC indica as características da relação comercial entre a cooperativa e o associado e informa sobre a periodicidade de pagamento e recebimento entre ambos. Quanto menor o valor de CFINC, mais adequada será a política comercial da cooperativa em relação ao 
cooperado, ou seja, esta não expõe suas finanças ao risco para praticar políticas de prazos junto ao cooperado.

Com base nos pesos recebidos nos indicadores e pela equação (1) é definida a nota para o tópico eficiência empresarial do empreendimento cooperativo (EECC).

O tópico eficiência empresarial da cooperativa enquanto organização (EEO) apresenta a capacidade de gerenciamento da cooperativa. Para isso, calculam-se os indicadores-índice de participação média da cooperativa no mercado regional (); ciclo financeiro da cooperativa (CFIN); margem operacional da cooperativa (MOC); e giro dos ativos permanentes (GAP).

No cálculo do consideram-se as atividades principais que a cooperativa desenvolve, pois ele indica a importância econômica da cooperativa para a região de atuação. Já a MOC informa sobre a qualidade dos gestores em administrar suas obrigações, enquanto o GAP apresenta a atuação dos gestores na imobilização de recursos; quanto maior o valor desses três indicadores, melhor será a eficiência empresarial da cooperativa.

O CFIN apresenta a eficiência comercial da cooperativa, que implica diretamente no seu fluxo de caixa. Portanto, quanto menor o valor desse indicador, mais eficiente será a gestão empresarial.

Na emissão do peso da MOC, do GAP e do CFIN devem ser comparados seus resultados com os resultados médios das cooperativas agropecuárias que atuam na mesma atividade que a cooperativa analisada.

Após calcular todos os indicadores e gerados seus respectivos pesos, é emitida uma nota para o tópico eficiência empresarial da cooperativa enquanto organização (EEO), conforme equação (1). 
Na avaliação do tópico profissionalização e qualidade da governança (PQG) são utilizados os indicadores que refletem as características dos gestores da cooperativa, quais sejam, relação contratual dos executivos ${ }^{8}$ com a cooperativa (RCE); formação e histórico dos executivos (FHE); e efetividade da fiscalização da gestão (EFG).

A RCE é feita para verificar o papel e a importância do executivo para o desempenho da cooperativa. Já a avaliação da FHE tem o intuito de informar sobre a capacitação dos principais executivos da cooperativa, enquanto a EFG indica se o conselho fiscal exerce sua atividade de forma adequada, ou seja, se garante que os gestores da cooperativa conduzem a organização de forma transparente, junto ao quadro social.

O diagnóstico é feito por meio de entrevistas com os diretores e da análise do estatuto social, dos livros de atas de reunião do conselho de administração e fiscal e dos relatórios de gestão.

A partir da análise de cada um dos indicadores é emitido seu peso e, pela equação (1), emite-se uma nota para o tópico.

Com base nas notas emitidas para cada tópico ou assuntos-chave e pela equação (2) emite-se a nota do grupo Capacidade da Organização.

O Capital da Organização, segundo grupo da metodologia, indica a situação econômica e financeira da cooperativa, possibilitando inferir se a sua condição financeira permitirá cumprir os compromissos contratados. Para gerar uma nota que transmita essas informações, são diagnosticados os seguintes assuntos-chave: capital social do cooperado (CSC); endividamento (END); autofinanciamento (AUTFIN); liquidez (LIQ); rentabilidade (RENT); e solvência (SOLV).

O assunto-chave capital social do cooperado (CSC) informa como a cooperativa faz sua alavancagem financeira via cooperado e mensura os indicadores capital social por cooperado (CSc) e capital social utilizado no giro (CSG)

\footnotetext{
${ }^{8}$ Segundo Michaeli (1998), executivo é a pessoa que ocupa uma posição de responsabilidade administrativa, de diretoria ou gerência, numa organização.
} 
O CSc indica a motivação do cooperado em transacionar com a sua cooperativa; quanto maior o seu valor, maior será o montante de capital social disponível à cooperativa. Por sua vez, o CSG informa quanto da necessidade de capital de giro é suprida pelo capital social do cooperado; quanto maior o seu valor, menor será a dependência de capital de terceiros no curto prazo. Com base nos pesos dados a cada indicador é dada a nota para o tópico (CSC), conforme equação (1).

Os indicadores utilizados para aferir o tópico endividamento demonstram qual a participação dos recursos de terceiros no financiamento da empresa e o grau de comprometimento financeiro da organização e permitem determinar a capacidade da cooperativa para cumprir seus compromissos financeiros.

$\mathrm{Na}$ avaliação desse assunto-chave utilizam-se os seguintes índices: grau de comprometimento do faturamento bruto da cooperativa com o endividamento junto a terceiros (GCFE); distribuição do endividamento total, no curto (DCPC) e longo prazo (DLPC); e grau de dependência de capital de terceiros para operacionalizar suas atividades (GDter).

O GCFE informa qual a percentagem da dívida saldada e se todo o faturamento foi destinado, exclusivamente, a essa finalidade; quanto menor seu valor, melhor será a gestão financeira da cooperativa. A distribuição das dívidas, quanto ao prazo de vencimento (DLPC - DCPC), apresenta a sua predominância, se no longo, se no curto prazo, e GDter informa sobre a dependência da cooperativa na captação de recursos no mercado para executar sua operações; quanto menor for seu valor, melhor será a situação financeira da organização.

Com base nos pesos recebidos por cada indicador é gerada uma nota para o endividamento, conforme equação (1).

De acordo com Oliveira Júnior (1991), o autofinanciamento representa a capacidade das cooperativas para gerirem suas operações com capital próprio. Serão apurados os indicadores quantidade de capital de giro 
disponível (CGD), necessidade de capital de giro (NCG) e índice de autofinanciamento (IAF).

O CGD representa o montante de recursos necessários, no curto prazo, para tornar possível a realização das operações da cooperativa, enquanto o NCG informa a quantidade de recursos necessários para a cooperativa realizar suas operações. O índice de autofinanciamento relaciona o CGD com a NCG e informa sobre sua real necessidade.

O IAF mensura a capacidade da cooperativa para financiar suas necessidades de capital de giro com seu próprio capital; assim, quanto maior seu valor, melhor será sua condição financeira.

Como o IAF é a relação entre a necessidade de capital de giro e o capital de giro disponível, então, baseado em seu valor, será emitida uma nota para informar sobre o tópico autofinanciamento.

De acordo com Brigham e Houston (1999), a posição de liquidez da empresa indica se esta consegue saldar suas dívidas, à medida que elas forem vencendo, durante o próximo exercício social. Na avaliação deste tópico utilizam-se os indicadores de liquidez corrente e seca, já consolidados na literatura de avaliação de empresas.

Com base nos pesos obtidos em cada um desses indicadores, é dada uma nota para o tópico liquidez (LIQ), conforme equação (1).

A rentabilidade, de acordo com Brigham e Houston (1999), é o resultado de uma série de políticas e decisões tomadas pelos gestores da empresa. Com base na definição dos autores, utilizam-se os seguintes indicadores para esse tópico-chave: margem líquida $(\mathrm{MgL})$; retorno sobre os ativos (RSA); e retorno sobre o patrimônio líquido (RSPL).

A margem líquida (MgL) apresenta o nível de segurança que os gestores da cooperativa aplicam sobre a unidade vendida, de forma a garantir o funcionamento da organização; quanto maior a $\mathrm{MgL}$, melhor será a condição financeira da cooperativa para pagar suas dívidas. 
O retorno sobre o ativo total informa a rentabilidade que este gera para a cooperativa e sobre o patrimônio líquido indica a taxa de retorno sobre os investimentos dos cooperados. Quanto maior esses valores, melhor será a rentabilidade da cooperativa.

Após avaliar os valores de MgL, RSA e RSPL e compará-los com os valores médios desses mesmos indicadores das cooperativas agropecuárias que exercem a mesma atividade, é gerado um peso para cada indicador. Com base nestes e pela equação (1), é calculada a nota para o tópico rentabilidade da cooperativa (RENT).

No tópico solvência (SOLV) é usado o índice de Kanitz, que informa a condição de solvência da empresa.

Após cálculo do indicador, com base no seu valor deverá ser emitida uma nota para o tópico solvência da cooperativa.

Com base nas notas recebidas em cada tópico e pela equação (2), é emitida a nota do grupo Capital da Organização.

O grupo Caráter da Organização apresenta a intenção da cooperativa em cumprir seus compromissos no curto prazo e no ambiente institucional vigente. Para gerar essa informação devem ser diagnosticados os seguintes tópicos: pontualidade nos pagamentos e existência de protestos e desabonos.

A pontualidade dos pagamentos é avaliada, conforme sugerido por Silva (1997), pelas chamadas informações comerciais e bancárias, que são dias de atraso de pagamento e freqüência dos atrasos.

Para averiguar esses indicadores é necessário analisar o valor de CFIN da cooperativa e questionar os gestores sobre os seguintes pontos: (a) quantas vezes a cooperativa atrasou os pagamentos, no último exercício social; e (b) em quantos dias consistiu esse atrasado. Obtidas as respostas, é preciso gerar uma nota para o tópico. 
O diagnóstico da existência de protestos e desabonos deve ser feito junto às empresas que prestam esse tipo de serviço ao mercado, ou seja, cartórios de protestos de títulos e empresas especializadas em fornecer históricos negativos, por exemplo, o SERASA e o Serviço de Proteção ao Crédito (SPC). Esse tipo de informação deve ser averiguado nos três últimos exercícios sociais, considerando um período de tempo próximo ao que as empresas que caracterizam histórico negativo disponibilizam no mercado. De acordo com os resultados do diagnóstico, deverá ser gerada uma nota para esse tópico.

Com base nas notas recebidas nos dois tópicos que compõem esse grupo e pela equação (2), é emitida a nota do Caráter da Organização.

O grupo Colateral e Conglomerado indica a relação societária da cooperativa com outras empresas ou cooperativas e o nível de garantias que pode ser fornecido em operações. Com base nas informações coletadas nesse grupo (Anexo B) e na pontuação estabelecida, conforme equação (1), é emitida a nota do grupo.

O grupo Condição do Mercado apresenta informações sobre o ambiente macroeconômico e permite averiguar se a cooperativa tem condições tanto internas quanto externas para cumprir seus compromissos nos prazos acordados.

Para gerar essa informação é necessário abordar temas relacionados com riscos do setor onde a cooperativa atua, ambiente político, econômico e regulatório e nível de apoio do estado nas avaliações.

Com base nas análises e nas informações coletadas para esse grupo, na pontuação estabelecida, conforme equação (1), é emitida sua nota.

Após análise de cada grupo, as cooperativas poderão ter avaliação de rating, como, por exemplo, AAAAA. Essa classificação representa que a organização avaliada teve ao menos $75 \%$ de peso 3 em cada indicador analisado e nota "a" em cerca de $75 \%$ dos tópicos avaliados em cada grupo. 
É importante realçar que a análise das notas obtidas pela cooperativa, baseada na proposta metodológica, irá variar conforme a necessidade do mercado. Por exemplo, se o interesse for averiguar o capital financeiro da cooperativa, a nota a ser analisada será segunda, ou seja, do grupo capital da organização. De forma semelhante, se a proposta for obter informações sobre a condição de mercado, então deverá ser analisada a quinta classificação no grupo.

\section{Aplicação da metodologia}

Para verificar a sua aplicabilidade, a metodologia foi aplicada em uma cooperativa agropecuária, por meio de estudo de caso.

A partir da aplicação da metodologia na cooperativa, foram geradas as notas de cada um dos tópicos, conforme Quadro 1. A cooperativa obteve notas "a", "b" e "c", e não houve concentração numa única nota. A distribuição destas permite inferir que a cooperativa possuía pontos que a expunham ao risco e outros que garantiam o cumprimento dos seus compromissos. 
Quadro 1 - Notas dos tópicos calculados no estudo de caso para a cooperativa

\begin{tabular}{|c|c|c|}
\hline Tópicos & Indicadores & Nota do tópico \\
\hline \multirow[t]{3}{*}{ Eficiência Social (ES) } & $\begin{array}{l}\text { ATc } \\
\text { PAG }\end{array}$ & \multirow[t]{3}{*}{$\mathrm{C}$} \\
\hline & CFCC & \\
\hline & ECVC & \\
\hline \multirow{5}{*}{$\begin{array}{l}\text { Estratégia Empresarial da Cooperativa com o } \\
\text { Cooperado (EECC) }\end{array}$} & PDCC & \multirow{5}{*}{$\mathrm{B}$} \\
\hline & RCSC & \\
\hline & PSC & \\
\hline & CFINC & \\
\hline & $\overline{\mathrm{IPM}} c$ & \\
\hline \multirow{3}{*}{$\begin{array}{l}\text { Eficiência Empresarial enquanto Organização } \\
\text { (EEO) }\end{array}$} & CFIN & \multirow[t]{4}{*}{ B } \\
\hline & MOC & \\
\hline & GAP & \\
\hline \multirow{3}{*}{$\begin{array}{l}\text { Profissionalização e Qualidade da Governança } \\
\text { (PQG) }\end{array}$} & $\mathrm{RCE}$ & \\
\hline & FHE & \multirow[t]{2}{*}{ B } \\
\hline & EFG & \\
\hline \multirow[t]{2}{*}{ Capital Social do Cooperado (CSC) } & $\begin{array}{c}\mathrm{CS}_{\mathrm{C}} \\
\mathrm{CSG}\end{array}$ & \multirow[t]{2}{*}{$\mathrm{C}$} \\
\hline & GCFE & \\
\hline \multirow[t]{2}{*}{ Endividamento (END) } & DLPC & \multirow[t]{2}{*}{$\mathrm{c}$} \\
\hline & GDTer & \\
\hline Autofinanciamento (AUTFIN) & IAF & $\mathrm{C}$ \\
\hline Liquidez (LIQ) & $\begin{array}{l}\mathrm{LC} \\
\mathrm{LS}\end{array}$ & \multirow[t]{2}{*}{$\mathrm{B}$} \\
\hline \multirow{3}{*}{ Rentabilidade (RENT) } & $\mathrm{MgL}$ & \\
\hline & RSA & \multirow[t]{2}{*}{ A } \\
\hline & RSPL & \\
\hline Solvência (SOLV) & KANITZ & A \\
\hline Pontualidade & & A \\
\hline Protestos e desabonos & & A \\
\hline
\end{tabular}


A partir das notas recebidas em cada um dos tópicos de assuntos-chave, foram emitidas as notas dos grupos, conforme exposto no Quadro 2.

Quadro 2 - Pontuação e notas obtidas pela cooperativa para os grupos estudados

\begin{tabular}{lc}
\hline \multicolumn{1}{c}{ Grupo } & Notas \\
\hline Capacidade da Organização & $\mathrm{B}$ \\
Capital da Organização & $\mathrm{B}$ \\
Caráter da Organização & $\mathrm{A}$ \\
Colateral e Conglomerado & $\mathrm{B}$ \\
Condição do Mercado & $\mathrm{A}$ \\
\hline
\end{tabular}

Portanto, a cooperativa em questão, de acordo com a análise, teve um rating corporativo igual a "BBABA".

O primeiro "B" significa que a cooperativa apresentava boa capacidade de organização, ou seja, boa competência para gerir suas atividades. A segunda nota informa que o capital da cooperativa era adequado às atividades de curto prazo, mas que poderá ser comprometido no futuro, se a gestão financeira não for adequada. Já a terceira nota ("A") indica que a cooperativa é cumpridora de seus compromissos; e a quarta, "B", que a cooperativa tem nível de garantias e colateral adequado às dívidas assumidas, porém suas estratégias junto a outras organizações não contribuem para elevar sua capacidade de pagamento. A última nota, "A", informa que a cooperativa atua num mercado com condição propícia, ou seja, permite cumprir seus compromissos de curto prazo. 


\section{Considerações finais e conclusões}

Durante a aplicação da metodologia, alguns indicadores não puderam ser calculados de imediato, pois a cooperativa não possuía informações suficientes no momento ou essa informação não estava disponível em fontes secundárias. Porém, esse fato não invalida a aplicação da metodologia no referido estudo de caso, ao contrário, conforme observado pelos próprios profissionais da cooperativa estudada, os indicadores são relevantes, possíveis de serem obtidos e deverão ser levados em consideração.

O peso de cada indicador facilitou a geração da nota para o tópico ao qual fazia parte, e todos os indicadores foram consistentes com a realidade da cooperativa.

Os tópicos abordados em cada grupo eram abrangentes, pois englobavam todos os assuntos que uma metodologia tradicional de rating corporativo aborda.

Os grupos, da forma como foram definidos, acompanhando os "Cs" do crédito, também foram adequados, pois abrangeram praticamente todas as áreas da organização, inclusive a influência do mercado na atividade da cooperativa.

A proposta de como chegar à avaliação do grupo (maiúscula), em função dos pesos diferentes para cada uma das avaliações dos tópicos, conforme equação 2 , também foi adequada, pois permite adição, diminuição ou substituição de tópicos em cada grupo.

O fato de a metodologia não utilizar uma única avaliação para representar as informações sobre a organização analisada, ao contrário do que é feito pelas agências de classificação, foi oportuno, pois o público que necessitar averiguar suas notas poderá fazê-lo de forma segmentada. Para as cooperativas, esse formato também será mais adequado, pois poderá mostrar ao público externo quais seus pontos fortes e, internamente, indicará quais os tópicos necessitam ser revisados para melhorar sua gestão. 
A metodologia mostrou-se aplicável e apresentou boa aproximação da realidade da cooperativa no mercado, conforme observação feita durante as visitas e avaliação da própria cooperativa. As notas finais da cooperativa estudada podem ser usadas como fonte de informações sobre gestão e, portanto, servem como redutores da assimetria de informação.

\section{Referências bibliográficas}

AKERLOF, G.A. The market for lemons: quality uncertainty and the market mechanism. Quarterly Journal of Economics, v.84, n.3, p.488500,1970 .

ALIANÇA COOPERATIVA INTERNACIONAL (ACI). Identidad y princípios cooperativos. Montevidéu: Editora Nordan Comunidad, 1995. 112p. Publicação da Declaração adotada pelo Congresso e Assembléia Geral de 1995 da A.C.I.

ARAUUJO, U.M. Assimetria de informação no crédito rural: aspectos teóricos e um modelo de classificação dos riscos dos créditos concedidos a cooperativas agropecuárias. Piracicaba, 1996. 81p. Tese (doutorado) - Escola Superior de Agricultura "Luiz de Queiroz", Universidade de São Paulo.

ARROW, R.H. The organization of economics activity: issues pertinent to choice of market versus non-market allocation. In: US Join Committee Congress, 91., Washington, 1969: Analysis and evolution of public expenditure. Washington: U.S. Government Office.1969. v.1

BERGAMINI JUNIOR, S. Classificação de Risco: o modelo em uso no BNDES. www.bndes.gov.br/conhecimento/publicações/catalogo/ rev_10a6.asp (20 out. 2004) 
BIALOSKORSKI NETO, S. Corporate governance and the role of the managers in brazilian cooperatives. http://www.fearp.usp.br/ sig/ ciriec.pdf (10 Feb. 2005)

BIALOSKORSKI NETO, S. (Ed.). Política institucional de monitoramento da autogestão das cooperativas do Estado de São Paulo: uma proposta preliminar de metodologia, pesquisa e implantação. São Paulo: s. ed. 2000. 127p.

BIALOSKOSRKI NETO, S.; NAGANO, M.S.; MORAES, M.B.C. Eficiência econômica de cooperativas agropecuárias: um modelo utilizando-se redes neurais. http://www.fearp.usp.br/ sig (10 jan. 2005)

BRIGHAM, E.F.; HOUSTON, J.F. Fundamentos da moderna administração financeira. São Paulo: Editora Campus, 1999. 713p.

COSTA, D.R.; BIALOSKORSKI NETO, S. Avaliação de risco e inadimplência de cooperativas agropecuárias brasileiras. In: CONGRESSO DA SOCIEDADE BRASILEIRA DE ECONOMIA E SOCIOLOGIA RURAL, n. 43, Ribeirão Preto, 2005. Anais. Ribeirão Preto: FEARP/USP - PENSA/USP, 2005. p. 213.

FARINA, E.M.M.Q.; AZEVEDO, P.F. de; SAES, M.S.M. Competitividade: mercado, estado e organizações. São Paulo: Editora Singular, 1997.285p.

GIMENES, R.M.T.; OPASO, M.A.U. Modelos multivariantes para a previsão de insolvência em cooperativas agropecuárias: uma comparação entre e análise discriminante e a análise de probabilidade condicional Logit. Caderno de Pesquisa em Administração, v.8, n.3, p.65-76, 2001.

MENEGÁRIO, A. H. Emprego de indicadores sócio-econômico na avaliação financeira de cooperativas agropecuárias. Piracicaba, 2000. 121p. Dissertação (Mestrado) - Escola Superior de Agricultura "Luiz de Queiroz", Universidade de São Paulo. 
MILGROM, P.; ROBERTS, J. Economics, organization \& management. New Jersey: Prentice Hall, 1992. 619p.

MOODY'S INVESTORS SERVICE. Rating actions. www.moody's.com (25 mar. 2004)

OLIVEIRA JUNIOR, C. C. Avaliação da eficiência empresarial das cooperativas. Curitiba: OCEPAR, 1991. 80p.

PINDYCK, R.S.; RUBINFELD, D.L. Microeconomia. 5.ed. São Paulo: Prentice Hall, 2002. 711p.

PINHO, D.B. (Org.). A empresa cooperativa: análise social, financeira e contábil. São Paulo: Coopercultura, 1986. 80p.

REQUEJO, L.M.H. Lack of monitoring agricultural cooperatives in Brazil: evidence and prospects for improvement. http:// www.agrosoft.org.br/trabalhos/ag97/w@w1600.htm (10 Oct. 2004)

SILVA, J. P. da. Análise e decisão de crédito. São Paulo: Editora Atlas, 1997.388p.

SPENCE, A.M. Market signaling: information transfer in hiring and related processes. Cambridge: Havard University Press, 1973. 221p.

ROTHSCHILD, M.; STIGLITZ, J.E. Equilibrium in competitive insurance markets: an essay on the economics of imperfect information. The Quarterly Journal of Economics, v.90, n.4, p.629-649, 1976.

STIGLITZ, J.E.; WEISS, A. Credit ration in market with imperfect information. The American Economic Review, v.71, n.3, p.393-410, 1981. 


\begin{abstract}
The macroeconomic and agricultural policy instability in the agricultural sector increased the cooperative needs to obtain resources in the financial markets. However, because the asymmetric information problem among directors, members and market, a rating methodology classification is necessary. The aim of this article is to propose a rating methodology that could improve the financial markets orientation. The methodology was developed and after applied in São Paulo State agricultural cooperative and the results allow concluding that methodology is feasible and represent adequately the institutional reality.
\end{abstract}

Key-words: agricultural cooperatives, rating methodology, Brazil. 


\section{ANEXO A - Fórmulas dos indicadores utilizados na metodologia}

\begin{tabular}{|c|c|}
\hline Indicador & Fórmula \\
\hline Índice de atividade econômica do cooperado com a cooperativa - ATc & $A T c=\frac{N C_{a}}{N C_{t}}$ \\
\hline Índice de abrangência do quadro social - AQS & $A Q S=\frac{N C_{t}}{N P_{t}}$ \\
\hline Índice de participação dos cooperados em assembléia geral - PAG & $\mathrm{PAG}=\frac{C A p_{t}}{N C_{t}}$ \\
\hline Eficiência Social da cooperativa - ES & $\mathrm{ES}=\frac{1}{\mathrm{n}_{i=1}} \sum_{i=1}^{n} X_{i}$ \\
\hline Índice de cobertura do financiamento efetuado pela cooperativa ao cooperado - CFCC & $\mathrm{CFCC}=\left(\frac{\mathrm{GDC}}{\mathrm{DCC}}\right)$ \\
\hline Ciclo financeiro da cooperativa junto ao cooperado - CFINC & $\begin{aligned} \mathrm{CFINC} & =\mathrm{PMRc}+\mathrm{PMEc}-\mathrm{PMPc} \\
\overline{\mathrm{IPM}}= & =\left(\sum_{t=1}^{n}(I P M)_{t} \times(P)_{t}\right)\end{aligned}$ \\
\hline Índice de participação média da cooperativa no mercado regional - IPMc & $\sum_{t=1}^{n}(P)_{t}$ \\
\hline Ciclo financeiro da cooperativa - CFIN & CFIN=PMR + PME - PMP \\
\hline Indicador & Fórmula \\
\hline Margem operacional da cooperativa - MOC & $M O C=\left(\frac{(\mathrm{RT}-\mathrm{CMV}-\mathrm{DO})}{\mathrm{RT}}\right) \times 100$ \\
\hline Giro dos ativos permanentes - GAP & $G A P=\frac{V P}{A P}$ \\
\hline Capital social por cooperado - CSc & $C S_{c}=\frac{C S_{r}}{N C_{t}}$ \\
\hline Capital social utilizado no giro - CSG & $C S G=\frac{C S_{r}}{N C G}$ \\
\hline $\begin{array}{l}\text { Grau de comprometimento do faturamento bruto da cooperativa com o endividamento } \\
\text { total junto a terceiros - GCFE }\end{array}$ & $G C F E=\left(\frac{P C+E x L P z}{F a t B}\right) \times 100$ \\
\hline Distribuição do endividamento total no curto prazo - DCPC & $D C P C=\left[\frac{P C}{P C+E x L p z}\right]$ \\
\hline Distribuição do endividamento total no longo prazo - DLPC & $D L P C=\left[\frac{E x L P z}{P C+E x L P z}\right]$ \\
\hline $\begin{array}{l}\text { Grau de dependência de capital de terceiros para operacionalizar suas atividades - } \\
\text { Gdter }\end{array}$ & $\begin{array}{c}\text { GDTer }=\left[\frac{(P C+E x L P z)}{P L}\right] \\
C G D=[(P L+E x L P)-(A P+R L p)] \times 1 C\end{array}$ \\
\hline Capital de giro disponível - CGD & $A T$ \\
\hline Necessidade de capital de giro - NCG & $N C G=\left(\frac{A O-P O}{A T}\right) \times 100$ \\
\hline Índice de autofinanciamento - IAF & $I A F=\frac{C G D}{N C G}$ \\
\hline Índice de Liquidez Corrente - LC & $L C=\frac{A C}{P C}$ \\
\hline Índice de Liquidez Seca - LS & $L S=\frac{(A C-E s t)}{P C}$ \\
\hline Margem líquida $-\mathrm{MgL}$ & $M g L=\frac{(S O B a)}{V T}$ \\
\hline Retorno sobre os ativos - RSA & $R S A=\frac{(S O B r e i)}{A T}$ \\
\hline $\begin{array}{l}\text { Retorno sobre o patrimônio líquido - RSPL } \\
\text { Índice de Kanitz }\end{array}$ & $\begin{array}{c}R S P L=\frac{(\text { SOBrei })}{P L} \\
K=0,05 R K p+0,65 L G+3,55 L S+1,06\end{array}$ \\
\hline
\end{tabular}




\section{ANEXO B: Check list sobre colateral e conglomerado}

\begin{tabular}{|c|c|c|c|}
\hline \multirow{2}{*}{\multicolumn{2}{|c|}{ Informações sobre a Cooperativa }} & \multicolumn{2}{|c|}{ Resposta } \\
\hline & & Sim & Não \\
\hline 01 & A cooperativa é acionista de empresas $\mathrm{S} / \mathrm{A}$ ? & & \\
\hline 02 & $\begin{array}{l}\text { As empresas de que a cooperativa é acionista geraram lucros no último } \\
\text { ano? }\end{array}$ & & \\
\hline 03 & Os lucros estão sendo distribuídos aos acionistas? & & \\
\hline 04 & $\begin{array}{l}\text { Os lucro s recebidos pela cooperativa, enquanto acionista, estão sendo } \\
\text { aplicados no FATES, conforme determina a lei 5764/71? }\end{array}$ & & \\
\hline 05 & $\begin{array}{l}\text { A conta FATES, prevista no PL da cooperativa, está desvinculada do } \\
\text { capital de giro? }\end{array}$ & & \\
\hline 06 & $\begin{array}{l}\text { O capital social da cooperativa na S/A pode ser utilizado como garantia de } \\
\text { operações? }\end{array}$ & & \\
\hline 07 & $\begin{array}{l}\text { A cooperativa é associada a uma cooperativa Central ou Federação de } \\
\text { cooperativas? }\end{array}$ & & \\
\hline 08 & A Central ou Federação tem gerado sobras nos últimos anos? & & \\
\hline 09 & As sobras da Central ou Federação estão sendo distribud́as às associadas? & & \\
\hline 10 & $\begin{array}{l}\text { O capital social da cooperativa na Central ou Federação pode ser utilizado } \\
\text { como garantia de operações? }\end{array}$ & & \\
\hline 11 & $\begin{array}{l}\text { Na sociedade da qual a cooperativa faz parte existem cláusulas de co - } \\
\text { responsabilidade no cumprimento das obrigaçoes que as partes assumem? }\end{array}$ & & \\
\hline 12 & $\begin{array}{l}\text { A sociedade contribui para aumentar o nível de garantia às operações da } \\
\text { cooperativa? }\end{array}$ & & \\
\hline 13 & $\begin{array}{l}\text { As sobras distribuídas pela cooperativa singular analisada estão sendo } \\
\text { incorporadas ao Patrimônio Líquido da cooperativa? }\end{array}$ & & \\
\hline 14 & $\begin{array}{l}\text { As sobras retidas pela cooperativa singular estão sendo capitalizadas na } \\
\text { conta capital social do cooperado? }\end{array}$ & & \\
\hline 15 & Existe intenção de fusão por parte da cooperativa analisada? & & \\
\hline 16 & $\begin{array}{l}\text { Existe intenção de incorporação de outra cooperativa por parte da } \\
\text { cooperativa analisada? }\end{array}$ & & \\
\hline 17 & O processo de fusão geraria economia de escala para a cooperativa? & & \\
\hline 18 & A incorporação geraria economia de escala para a cooperativa? & & \\
\hline 19 & A cooperativa analisada está vinculada a uma cooperativa de crédito rural? & & \\
\hline 20 & $\begin{array}{l}\text { As operações d a cooperativa de crédito rural podem ser definidas como } \\
\text { benéficas à cooperativa analisada? }\end{array}$ & & \\
\hline 21 & Os ativos reais da cooperativa podem ser dados como garantia do contrato? & & \\
\hline 22 & $\begin{array}{l}\text { Os ativos reais a serem dados em garantia já estão como garantia de outro } \\
\text { contrato? }\end{array}$ & & \\
\hline 23 & $\begin{array}{l}\text { Os imóveis a serem dados em garantia estão em adequado estado de } \\
\text { conservação? }\end{array}$ & & \\
\hline 24 & Existem outros ativos reais que poderão ser dados como garantia? & & \\
\hline 25 & Existiria liquidez para as garantias reais dadas ao contrato? & & \\
\hline 26 & Existem avalistas para o contrato? & & \\
\hline 27 & $\begin{array}{l}\text { Os diretores têm ativos suficientes para serem fiadores do contrato, caso a } \\
\text { cooperativa não o cumpra? }\end{array}$ & & \\
\hline 28 & $\begin{array}{l}\text { O valor total das garantias, adicionados dos fiadores, é suficiente para a } \\
\text { realização do contrato? }\end{array}$ & & \\
\hline 29 & $\begin{array}{l}\text { A cooperativa executa al ianças estratégias com outras empresas ou } \\
\text { cooperativas? }\end{array}$ & & \\
\hline 30 & $\begin{array}{l}\text { Essa aliança contribui para o cumprimento dos compromissos assumidos } \\
\text { pela cooperativa? }\end{array}$ & & \\
\hline
\end{tabular}


REVISTA DE ECONOMIA E AGRONEGÓCIO, VOL.3, $N^{\circ} 4$ 